\title{
Mechanical Behavior of Red Sandstone under Incremental Uniaxial Cyclical Compressive and Tensile Loading
}

\author{
Baoyun Zhao, ${ }^{1,2}$ Dongyan Liu, ${ }^{1}$ Tianzhu Huang, ${ }^{1}$ Wei Huang, ${ }^{1}$ and Wei Liu ${ }^{3}$ \\ ${ }^{1}$ School of Civil Engineering and Architecture, Chongqing University of Science and Technology, Chongqing 401331, China \\ ${ }^{2}$ Department of Civil and Environmental Engineering, North Dakota State University, Fargo, ND 58108-6050, USA \\ ${ }^{3}$ No. 208 Hydrogeology and Engineering Geology Team, Chongqing Bureau of Geology and Minerals Exploration, \\ Chongqing 400700, China
}

Correspondence should be addressed to Baoyun Zhao; baoyun666@163.com

Received 19 June 2017; Revised 19 September 2017; Accepted 4 December 2017; Published 31 December 2017

Academic Editor: Longjun Dong

Copyright (C) 2017 Baoyun Zhao et al. This is an open access article distributed under the Creative Commons Attribution License, which permits unrestricted use, distribution, and reproduction in any medium, provided the original work is properly cited.

\begin{abstract}
Uniaxial experiments were carried out on red sandstone specimens to investigate their short-term and creep mechanical behavior under incremental cyclic compressive and tensile loading. First, based on the results of short-term uniaxial incremental cyclic compressive and tensile loading experiments, deformation characteristics and energy dissipation were analyzed. The results show that the stress-strain curve of red sandstone has an obvious memory effect in the compressive and tensile loading stages. The strains at peak stresses and residual strains increase with the cycle number. Energy dissipation, defined as the area of the hysteresis loop in the stress-strain curves, increases nearly in a power function with the cycle number. Creep test of the red sandstone was also conducted. Results show that the creep curve under each compressive or tensile stress level can be divided into decay and steady stages, which cannot be described by the conventional Burgers model. Therefore, an improved Burgers creep model of rock material is constructed through viscoplastic mechanics, which agrees very well with the experimental results and can describe the creep behavior of red sandstone better than the Burgers creep model.
\end{abstract}

\section{Introduction}

In many rock engineering fields such as underground excavation, rock slope engineering, and mining, rock materials often experience cyclic loading [1]. It is well known that the mechanical behavior of rocks under cyclic loads differs dramatically from that under static loads [2]. Therefore, it is necessary to understand the response of rock mass under cyclic loads.

Laboratory testing is the main method to understand the mechanical behaviors of rock mass. Therefore, in the past several decades, extensive investigations have been carried out on the mechanical behavior of rock mass under cyclic uniaxial or triaxial compressive loads on the basis of laboratory experimental results. Based on the uniaxial cyclic compression test results, Ge et al. [3] discussed the threshold of axial stress for fatigue failure of rocks. Ma et al. [4] and Fuenkajorn and Phueakphum [5] investigated
Young's modulus degradation with loading cycles. Huang and Li [6] investigated the characteristics of strain energy accumulation, dissipation, and release based on the axisymmetric triaxial compression loading-unloading test results. He et al. [7] carried out an experimental investigation of strength and fatigue properties of intact sandstone samples subjected to dynamic cyclic loading in the laboratory. Erarslan and Williams [8] examined the damage mechanism of rock fatigue and its relationship to the fracture toughness of rocks using Brisbane tuff disc specimens. Zhao et al. [9] analyzed the creep behavior of intact and cracked limestone by a series of triaxial creep tests under multilevel loading and unloading cycles.

The above experimental results provide a better foundation for the construction of a damage evolution equation and a creep model under cyclic compression load. Liu et al. [10] proposed a damage evolution equation for rock salt under uniaxial compression loading condition. Wang et al. 
[11] proposed a constitutive model for the fatigue behavior of rocks subjected to cyclic loading according to the triaxial compression test results. Liu et al. [12] developed a new damage constitutive model through energy dissipation to describe the behavior of rocks under uniaxial compression cyclic loading. Yang et al. [13] constructed a viscoelastoplastic creep model of rock material, which can better describe the triaxial compressive loading and unloading creep behavior of marble. Khaledi et al. [14] employed an elastoviscoplastic creep model to predict the stress-strain relation around the cavern during the construction and cyclic operation phases.

It is noteworthy that the abovementioned studies mainly focus on the mechanical behavior of rocks under cyclic loads of compressive loading and unloading, while the stability of many geotechnical engineering processes, such as underground excavation, mining tunnel, and slope, may be dominated by tensile stress. Since the tensile creep rupture strength of red sandstone is about $1 / 40$ of its compressive creep rupture strength [15], it is very necessary to consider the tensile stress in the mechanical behavior study of red sandstone under cyclic loading.

To better understand the uniaxial mechanical behavior of deep rock mass, short-term and creep tests were conducted for red sandstone located at an underground tunnel in Chongqing city under uniaxial cyclic incremental compressive and tensile loading. Based on the short-term uniaxial cyclic experimental results for red sandstone, the strain at peak stress, residual strain, area of hysteresis loop, and energy dissipation behavior of red sandstone were first analyzed. In accordance with creep experimental results, Burgers creep model was used to describe the behavior of the red sandstone, but it was found to be not fitting with the experimental data very well. Thus, an improved Burgers creep model was constructed to capture experimental results of red sandstone creep under cyclic compressive and tensile loading. The comparison of the improved Burgers creep model with the experimental results shows an excellent match and verifies the validity of the suggested model.

\section{Specimens and Method}

2.1. Specimen Preparation. Sandstone specimens for incremental uniaxial cyclical testing were collected from a deep underground tunnel in Chongqing city. Sandstone in this area is red. The average unit weight is about $2380 \mathrm{~kg} / \mathrm{m}^{3}$. According to the method suggested by ISRM, all tested sandstone specimens are cylindrical with a diameter of $50 \mathrm{~mm}$ and a length of $100 \mathrm{~mm}$ approximately (see Figure 1). More than 15 specimens were prepared for the tests: three specimens (numbers 1 3) for conventional uniaxial compression experiments, three specimens (numbers 4 6) for conventional uniaxial tensile experiments, one specimen (number 7) for incremental uniaxial cyclical compressive and tensile loading test, and one specimen (number 8) for incremental uniaxial cyclical compressive and tensile loading creep test, and the remaining specimens were prepared for compensatory tests.

2.2. Testing Equipment. Both conventional experiments (including uniaxial compression and tension) and incremental

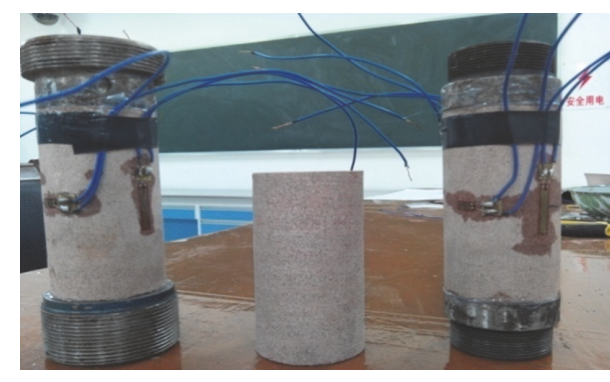

FIGURE 1: Rock specimens.

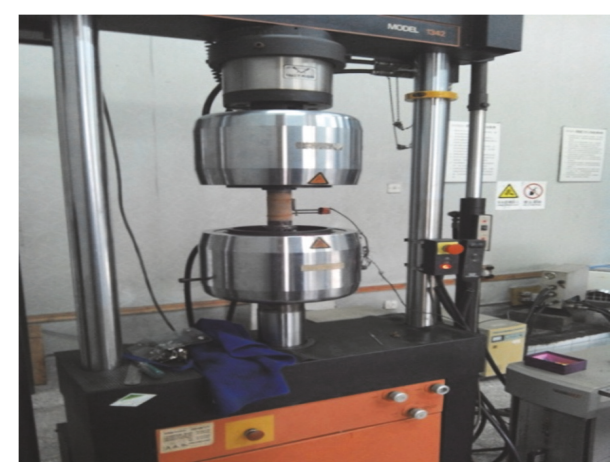

FIGURE 2: Experimenting machine of INSTRON 1342.

cyclic experiments of specimens were carried out using a servo-controlled experiment machine INSTRON 1342 with axial loading in the range of $0-200 \mathrm{kN}$. The experimental setup and deformation sensor measurement system are shown in Figure 2. The cyclic incremental uniaxial compressive and tensile creep experiments of specimens were carried out using a self-made lever-type tensile and compression rheological tester (see Figure 3). By removing the tension supporting bar, the tester can apply compressive loads, and by adding this supporting bar and removing the transfer bolt, the tester can apply tensile loads easily [16].

To avoid the eccentric force under cyclic compressive and tensile loading, a self-made specimen holding device [15] was also used in both short-term and creep cyclic loading tests. The specimen holding device is shown in Figure 4.

2.3. Experimental Setup. Two different kinds of incremental uniaxial cyclic compressive and tensile loading tests were conducted in this research, which were short-term incremental compressive and tensile cyclic loading test and incremental compressive and tensile cyclic loading creep test, as shown in Figures 5(a) and 5(b), respectively.

The procedure of incremental cyclic compressive and tensile loading test can be described as follows: first, the specimens are installed on the specimen holding device by using high performance resin adhesive, and at least 48 hours is required for the adhesive to be cured (as shown in Figure 4). The holding device was then placed on the testing machine. A loading rate of $0.005 \mathrm{~mm} / \mathrm{min}$ was used to give the specimen cyclic loading paths of compressive loading, compressive unloading, tensile loading, and tensile unloading. Different 


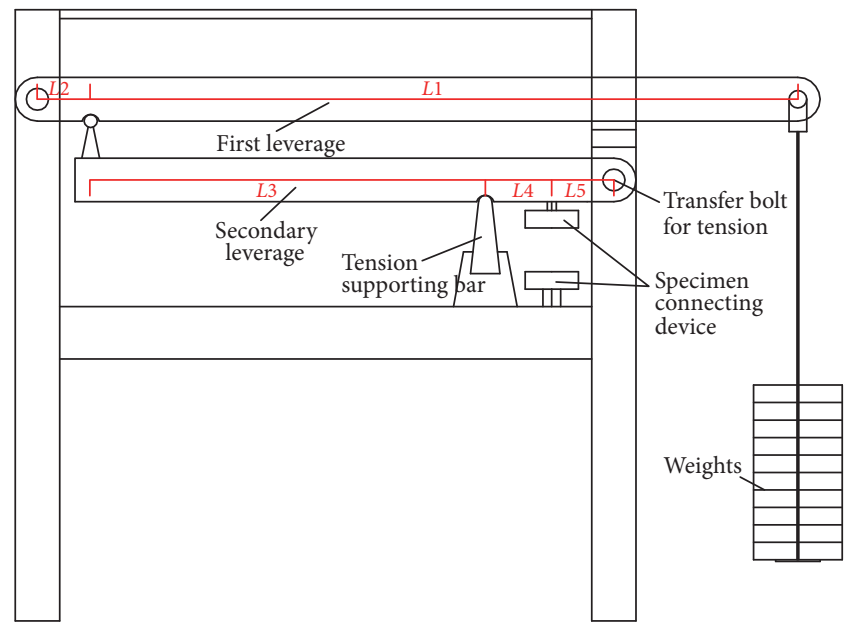

(a) Schema of the rheological tester

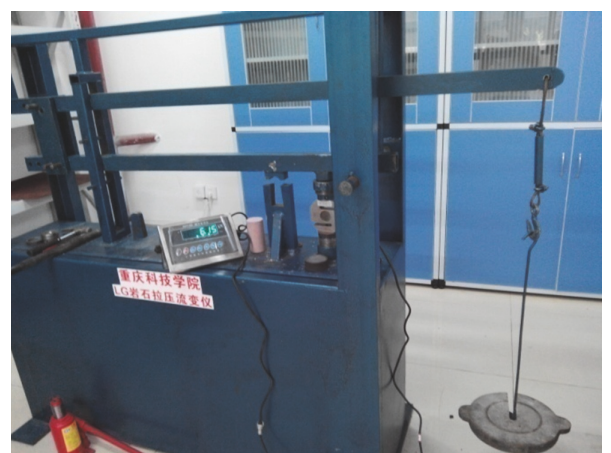

(b) Photo of cyclic creep testing equipment

FIGURE 3: A lever-type tensile and a compression rheological tester [16].

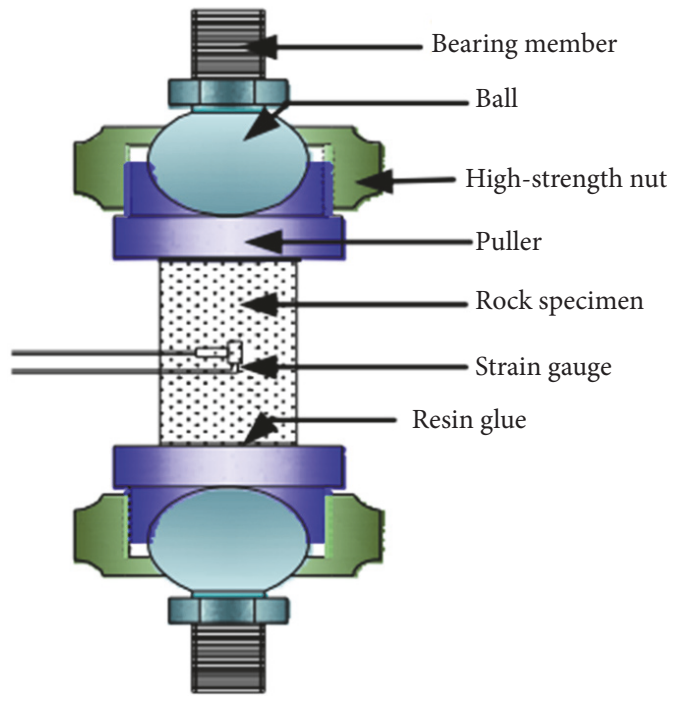

Figure 4: Specimen holding device [15].

stress levels such as $20 \%, 40 \%, 60 \%$, and $80 \%$ of the specimen's average uniaxial tensile and compressive strength are used (Figure 5(a)).

The procedure of cyclic incremental compressive and tensile creep loading test was conducted on another specimen (number 8). In the creep experiments, stress levels are also $20 \%, 40 \%, 60 \%$, and $80 \%$ of the specimen's average uniaxial tensile and compressive strength, which are the same as the short-term stress levels, as shown in Figure 5(b). The duration for each stress level (each compressive or tensile stress stage) was about 12 hours. Calculated weights were used to apply the compressive and tensile stress levels. Before switching between the compressive and tension phase, each kind of stress will be removed. For minimum influence on the testing results, the load switch procedure needs to be completed in two minutes. The electrical resistance strain gauges were used to measure the axial strain and the lateral strain of the specimens (as shown in Figure 1). Gauges with the size of $3 \times 5 \mathrm{~mm}$ were used to measure the lateral strain of the specimens and gauges with the size of $3 \times 20 \mathrm{~mm}$ were used to measure the axial strain. All the electrical resistance strain gauges have the same resistances which are 120 ohms.

\section{Experimental Results and Discussions}

3.1. Conventional Uniaxial Tests Results. Before the cyclic loading tests, conventional uniaxial compression and tension tests for the red sandstone samples were carried out to measure their short-term strength and deformation behavior. Figures 6 and 7 show the typical curves of stress versus strains of sandstone specimens under compression and direct tension, respectively. The volumetric strain during the tests was calculated by the axial and the lateral strain from (1). In accordance with the stress-strain curves of red sandstone specimens under uniaxial compressive loading, the compression deformation of red sandstone can be divided into four stages (Figure 6): (I) pore and fissure closure, (II) elastic deformation, (III) crack growth, and (IV) postpeak softening, as shown in Figure 6. The uniaxial compressive strengths of the specimens (numbers 1-3) are 52.85 MPa, 56.55 MPa, and $53.57 \mathrm{MPa}$, respectively, with an average value of $54.32 \mathrm{MPa}$. While there are two or three stages in the stress-strain curves of red sandstone specimens (numbers 4-6) under uniaxial tensile loading, the stages are (I) elastic deformation, (II) crack growth, and (III) postpeak softening, as shown in Figure 7. The uniaxial tensile strengths of the specimens (numbers 4-6) are $-1.39 \mathrm{MPa}, 1.41 \mathrm{MPa}$, and $-1.40 \mathrm{MPa}$, respectively, with an average value of $-1.40 \mathrm{MPa}$.

$$
\varepsilon_{v}=\varepsilon_{1}+2 \varepsilon_{3}
$$

where $\varepsilon_{1}$ is the axial strain, $\varepsilon_{3}$ is the lateral strain, and $\varepsilon_{v}$ is the volumetric strain. 




(a) Short-term compressive and tensile cyclic loading test

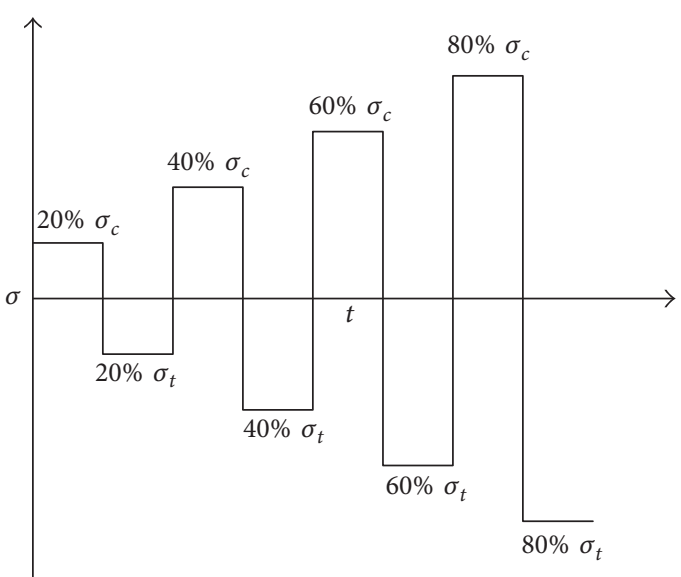

(b) Compressive and tensile cyclic loading creep test

FIGURE 5: The sketch of incremental compressive and tensile cyclic loading.

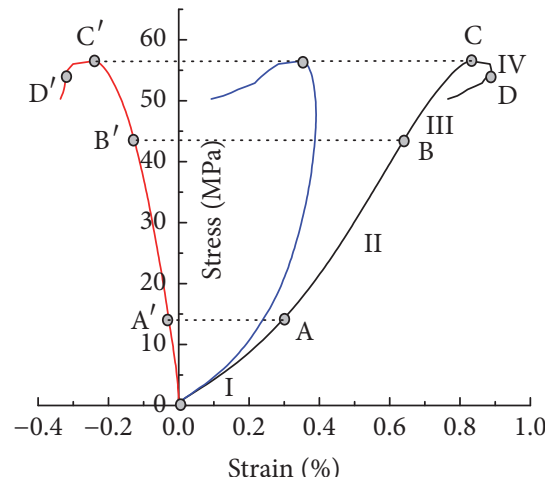

Strain $(\%)$



(a) Specimen number 1

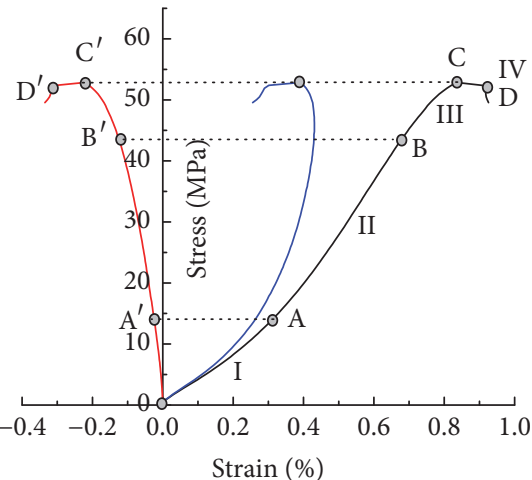

Strain $(\%)$

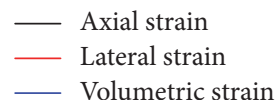

(b) Specimen number 2
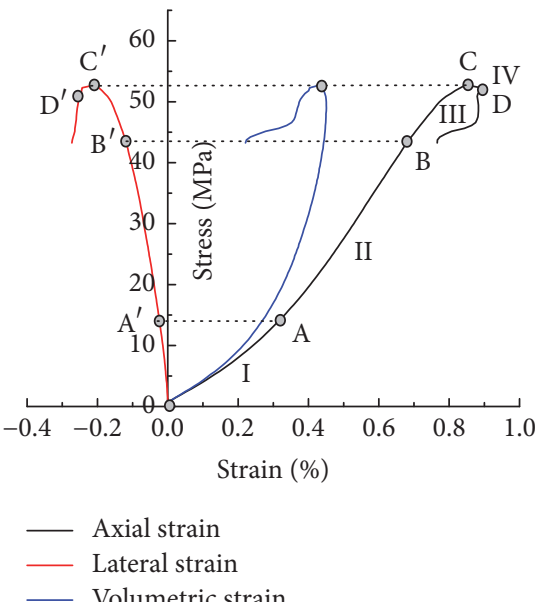

(c) Specimen number 3

FIgURE 6: Typical curves of stress versus axial strain of sandstone specimens under compression.

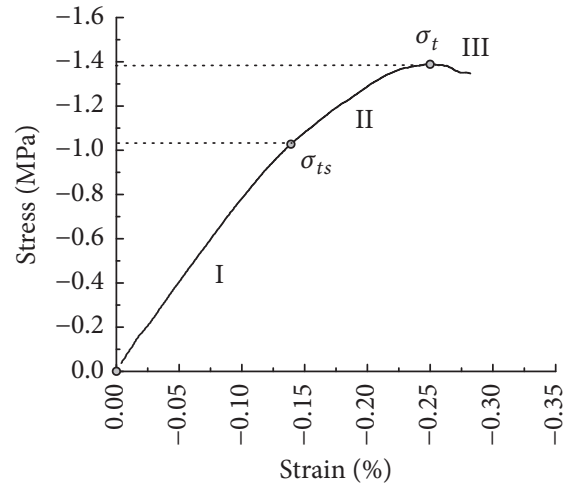

- Axial strain

(a) Specimen number 4

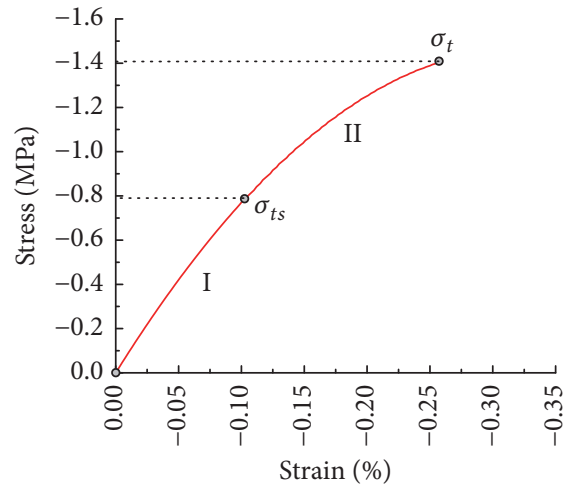

- Axial strain

(b) Specimen number 5



(c) Specimen number 6

FIGURE 7: Typical curves of stress versus axial strain of sandstone specimens under direct tension. 


\subsection{Mechanical Behavior under Short-Term Cyclic Loading}

3.2.1. Deformation Characteristics. The relationship between stress and axial strain of red sandstone specimens under the cyclic incremental uniaxial compressive and tensile stress is shown in Figure 8. The maximum compressive stresses in Figure 8 are $10.86 \mathrm{MPa}, 21.73 \mathrm{MPa}, 32.59 \mathrm{MPa}$, and $43.46 \mathrm{MPa}$, respectively, and the maximum tensile stresses in Figure 8 are $-0.28 \mathrm{MPa},-0.56 \mathrm{MPa},-0.84 \mathrm{MPa}$, and $-1.12 \mathrm{MPa}$, respectively. It can be seen from Figure 8 that the curve of stress-strain formed hysteretic loops after each stress path of compressive loading, compressive unloading, tensile loading, and tensile unloading and that the area of the hysteretic loops increased with the increasing of the loading stress. It was also found that the stress-strain curves in the compressive loading stages and the tensile loading stages were overlapped.

There is a certain value of residual strain after each cyclic load. Figure 9 shows the strain at peak stress and the residual strains with cycle number. It was found that the strains at the peak compressive stress increase nearly linearly with the increase of the cycle number, while the power function can better express the relationship between the strains at peak tensile and the cycle number and the relationship between the residual strains and the cycle number.

3.2.2. Energy Dissipation Characteristics. Rock is a natural geological material containing joints and microcracks. Cyclic compressive and tensile loads will cause microcracks to coalesce, develop, and extend, and the whole process subsequently causes energy dissipation. The considered dissipated energy in each loading cycle $\left(W_{\text {diss }}\right)$ can be obtained by calculating the area defined by the hysteresis loop in the stress-strain curves [17]. Since the zone between the loading and unloading stress-strain curves represents the dissipated energy density $w$ [18], the dissipated energy $W_{\text {diss }}$ can be expressed as [19]

$$
W_{\text {diss }}=A L \int \sigma_{1} d \varepsilon_{1}=A L w
$$

where $W_{\text {diss }}$ is the dissipated energy, $w$ is the dissipated energy density, $A$ is the cross-sectional area of the specimen, $L$ is the length of the specimen, and $\sigma_{1}$ and $\varepsilon_{1}$ are the corresponding stress and strain.

According to (2), the dissipated energy of the red sandstone was calculated in each cycle loop, and the relationship between the dissipated energy and the cycle number is shown in Figure 10. It was found that the dissipated energy increases nearly in a power function with the cycle number.

\subsection{Creep Behavior of the Specimens under Cyclic Loading}

3.3.1. Cyclic Creep Test Results. In accordance with the testing procedure shown in Figure 5(b), cyclic loading creep test results of red sandstone with different uniaxial compressive and tensile stress were obtained, as shown in Figure 11. The stress levels were the same as these of the short-term compressive and tensile cyclic loading tests, and they lasted for about 12 hours at each compressive or tensile stress level.

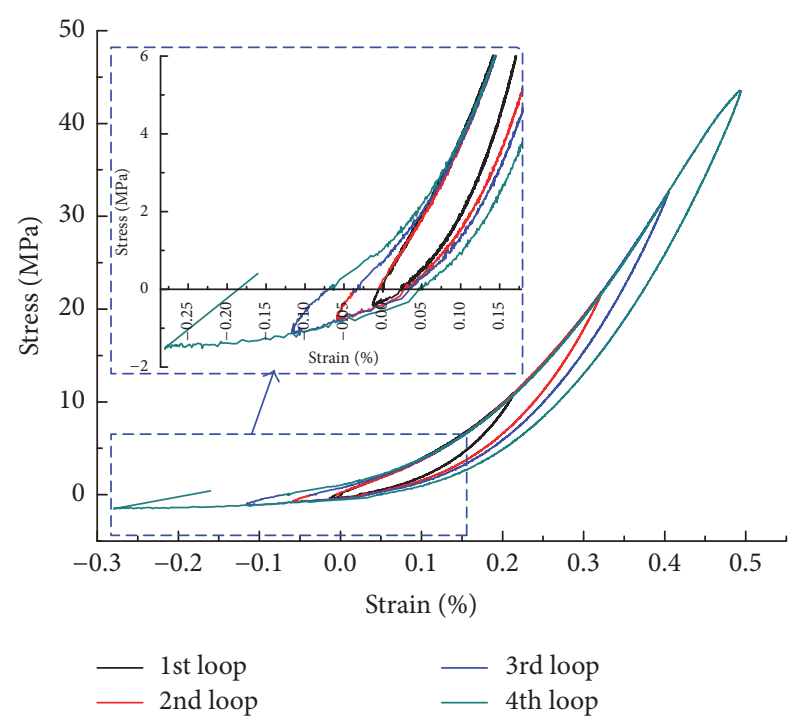

FIGURE 8: Stress-strain curve under incremental uniaxial compressive and tensile stress.

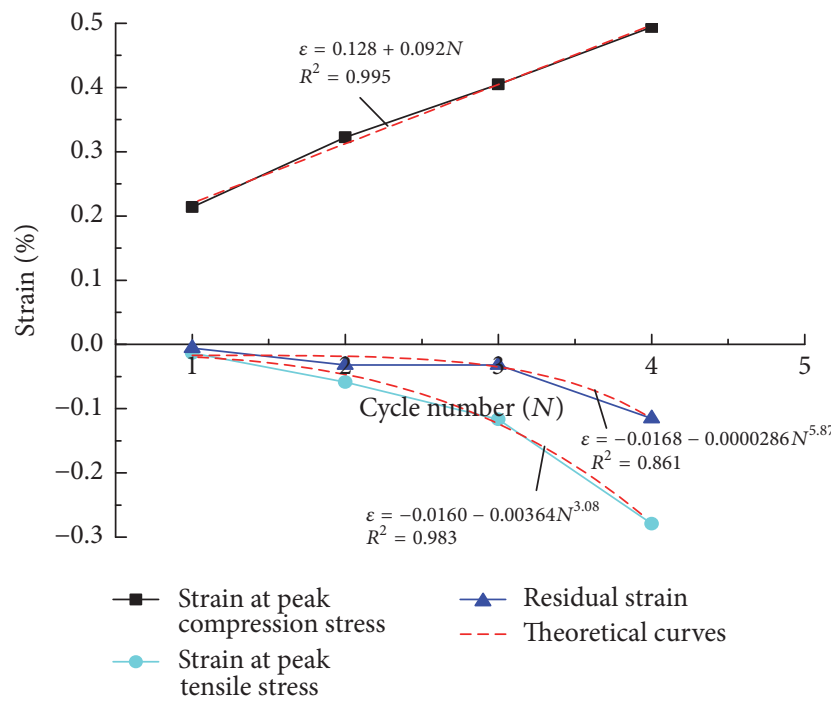

FIGURE 9: Curves of strains at peak stress point and residual strains versus cycle number.

It can be deduced from Figure 11 that, for each compressive or tensile stress level, the axial and the lateral strain rates increase first and then gradually decrease to a constant value after a period of time. According to the evolution of the creep strain, the creep curve under each stress level can be divided into decay and steady stages.

\subsubsection{Creep Model and Parameter Identification}

(1) Burgers Creep Model and Parameter Identification. According to the creep data of the red sandstone under compressive and tensile stress (Figure 11), there exists instantaneous strain, decay creep, and steady creep under each stress level of compressive or tensile stress stages, and the steady creep strain approaches a certain constant value with time. Therefore, it is 


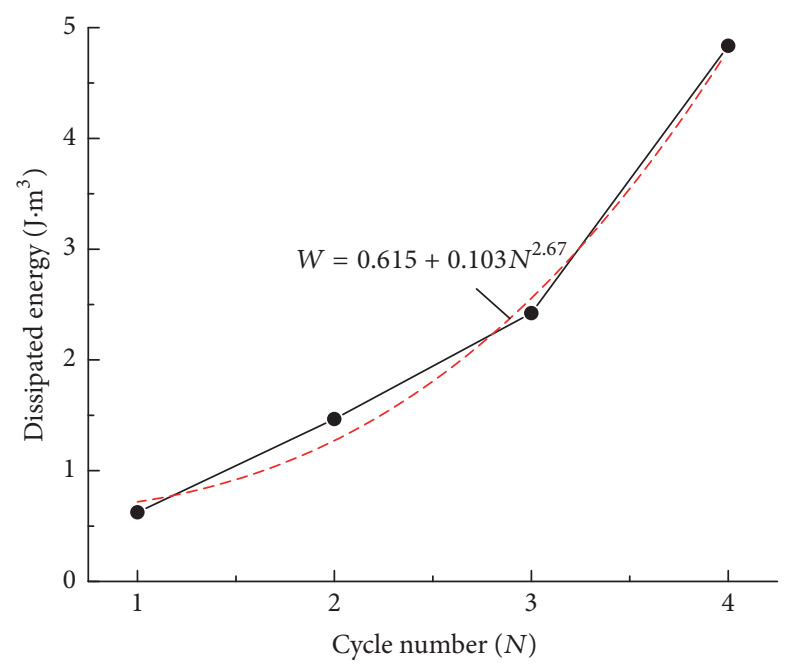

FIGURE 10: Relationship between the dissipated energy and the cycle number.



(a)

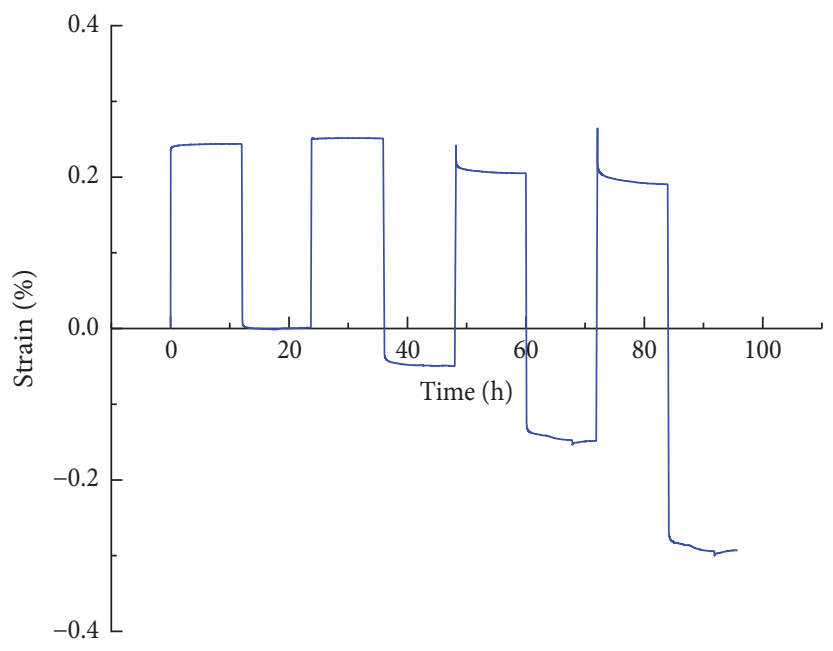

(b)

FIGURE 11: Curves of strain versus time of sandstone specimens under cyclic compressive and tensile stress: (a) axial and lateral strain and (b) volumetric strain.

necessary to simulate the creep behavior of rocks by using a creep model. As we all know, the creep curve of Burgers creep model starts with transient deformation, and then it grows in an exponential decline rate and tends to be constant [20], which can be regarded as the combination of the Maxwell model and Kelvin model.

The creep function of the Burgers creep model is

$$
\varepsilon=\frac{\sigma}{E_{1}}+\frac{\sigma}{\eta_{1}} t+\frac{\sigma}{E_{2}}\left(1-\exp \left(-\frac{E_{2}}{\eta_{2}} t\right)\right)
$$

where $\sigma$ is the stress; $E_{1}$ and $E_{2}$ are the elastic moduli; $\eta_{1}$ and $\eta_{2}$ are the viscosity coefficients.

Take the processed data of axial creep as an example; in accordance with (3), the creep parameters $\left(E_{1}, \eta_{1} E_{2}, \eta_{2}\right)$ for Burgers model can be identified by the nonlinear curve fitting. The identified Burgers creep model parameters are listed in Table 1, and Figure 12 presents a comparison of the Burgers creep model curves and the experimental results for red sandstone. From Figure 12 and Table 1, we can see that Burgers creep model can describe the creep behavior of the red sandstone under the cyclic incremental uniaxial compressive and tensile stress, but the precision of the model still needs improving.

From Table 1, it also can be seen that, under the compressive stress, the elastic parameters $E_{1}$ and $\eta_{1}$ vary slightly with the increase of stress. The parameter $E_{2}$ decreases with the increase of stress, whereas the parameter $\eta_{2}$ has no marked relationship with the stress. However, the parameters $E_{2}$ and 


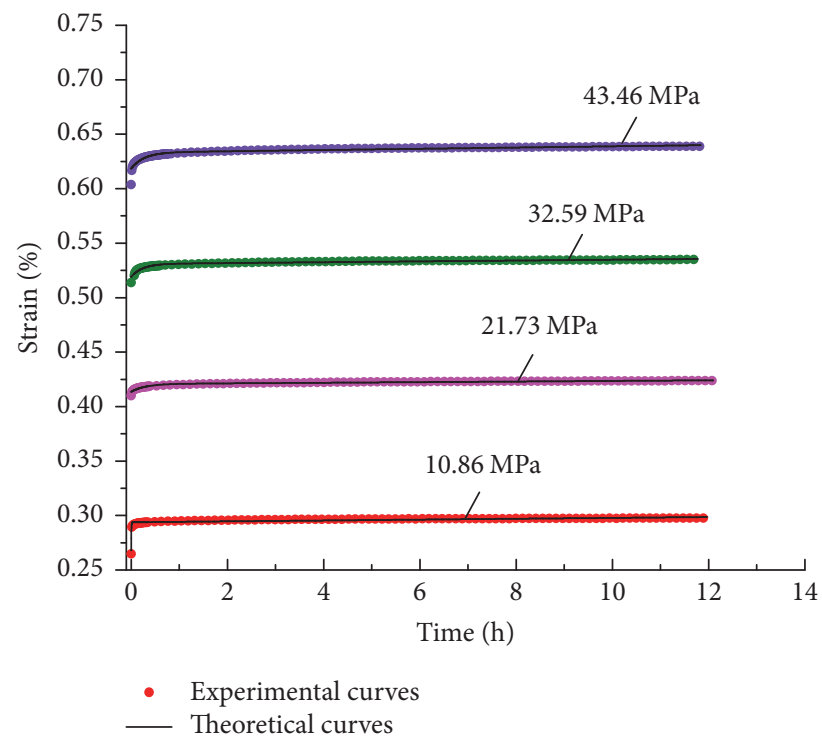

(a)

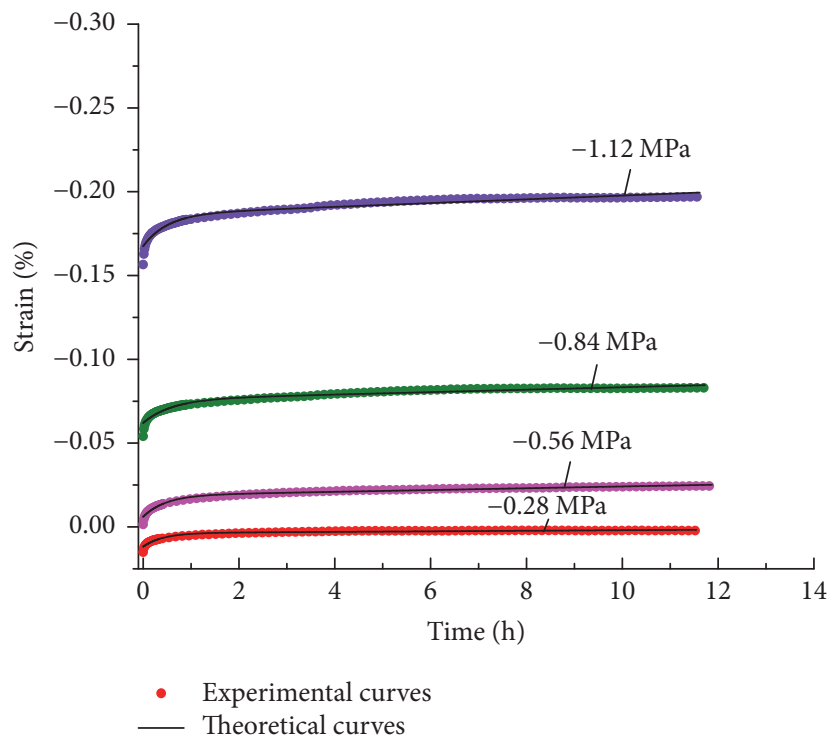

(b)

FIGURE 12: Comparison between Burgers creep model curves with the experimental result (a) under compressive stress and (b) under tensile stress.

TABLE 1: Burgers creep model parameters of red sandstone.

\begin{tabular}{|c|c|c|c|c|c|}
\hline$\sigma(\mathrm{MPa})$ & $E_{1}(\mathrm{MPa})$ & $\eta_{1}(\mathrm{MPa} \cdot \mathrm{h})$ & $E_{2}(\mathrm{MPa})$ & $\eta_{2}(\mathrm{MPa} \cdot \mathrm{h})$ & $R 2$ \\
\hline 10.86 & 4050.14 & 2731654.32 & 42273.41 & 209.75 & 0.827 \\
\hline 21.73 & 5254.52 & 7795505.19 & 301936.79 & 87284.57 & 0.978 \\
\hline 32.59 & 6279.33 & 8455407.36 & 272555.11 & 63324.74 & 0.963 \\
\hline 43.46 & 7027.61 & 7675487.69 & 293402.52 & 77424.65 & 0.954 \\
\hline-0.28 & -2379.26 & 168450.11 & 3438.36 & 1395.44 & 0.976 \\
\hline-0.56 & 9210.78 & 105074.47 & 4397.46 & 2042.85 & 0.987 \\
\hline-0.84 & 1353.98 & 115643.16 & 5988.89 & 3541.60 & 0.974 \\
\hline-1.12 & 667.00 & 112377.40 & 5757.59 & 3254.71 & 0.973 \\
\hline
\end{tabular}

$\eta_{2}$ increase with the stress and $\eta_{1}$ decreases with the stress under tensile stress. It is noteworthy that, due to the positive strain value, the parameter $E_{1}$ is $-2379.26 \mathrm{MPa}$ under the stress of $-0.28 \mathrm{MPa}$. So, it can be obtained that the loading stress value, as well as the stress condition, was of great significance and affected the Burgers creep model parameters of red sandstone.

(2) Improved Burgers Creep Model and Parameter Identification. It can be obtained from Figure 11 that the axial and the lateral creep curves show obvious nonlinear behavior; the instantaneous strain, decay creep, and steady creep reveal a trend of increase with the cycle number and cycle loading, indicating that both the cycle number and the level of the stress are the primary reason for the nonlinear behavior of the red stone under uniaxial cyclic loading.

In order to better describe the creep behavior of red sandstone material under cyclic incremental uniaxial compressive and tensile stress, by adopting the decreasing hypothesis of viscosity coefficient [21-23], an improved Burgers creep model of rock material can be proposed, as shown in Figure 13.
The creep equation of the improved Burgers creep model can be written as

$$
\varepsilon=\frac{\sigma}{E_{1}}+\frac{\sigma}{E_{2}}\left(1-\exp \left(-\frac{E_{2}}{\eta_{2}} t\right)\right)+\frac{\sigma}{\eta(n, t)} t,
$$

where $\sigma$ and $\varepsilon$ are the creep stress and creep strain, respectively; $E_{1}$ and $E_{2}$ are the elastic moduli; $\eta_{2}$ is the viscosity coefficient; $t$ is the creep time under each creep stress level.

Here, $\eta(n, t)$ can be expressed as

$$
\eta(n, t)=\eta_{0} \frac{t^{n-1}}{t_{0}^{n-1}}
$$

where $\eta_{0}$ is the initial viscosity coefficient; $t_{0}$ is the unit time, whose value is 1 ; and $n$ is the creep parameter, which is related to the cycle number and cycle loading.

Based on the creep test data under compressive and tensile stresses, the relevant parameters of the improved Burgers creep model were identified from data processing, as shown in Table 2. The calculated results of the creep curves and the tested ones are shown in Figure 14, and 
TABLE 2: Improved Burgers creep model parameters of red sandstone.

\begin{tabular}{|c|c|c|c|c|c|c|}
\hline$\sum(\mathrm{MPa})$ & $E_{1}(\mathrm{MPa})$ & $E_{2}(\mathrm{MPa})$ & $\eta_{2}(\mathrm{MPa} \cdot \mathrm{h})$ & $\eta_{0}(\mathrm{MPa} \cdot \mathrm{h})$ & $n$ & $R^{2}$ \\
\hline 10.86 & 4101.21 & 57010.75 & 154.76 & 100171.55 & 0.101 & 0.982 \\
\hline 21.73 & 5313.05 & 661873.20 & 104699.32 & 276591.10 & 0.155 & 0.997 \\
\hline 32.59 & 6368.00 & 316958.07 & 33275.06 & 392902.99 & 0.184 & 0.990 \\
\hline 43.46 & 7219.34 & 517211.08 & 48227.04 & 197992.56 & 0.111 & 0.994 \\
\hline-0.28 & -1724.62 & 5574.04 & 2060.16 & 4000.58 & 0.122 & 0.990 \\
\hline-0.56 & 37340.00 & 9066.80 & 3328.24 & 5667.07 & 0.220 & 0.997 \\
\hline-0.84 & 1670.03 & 21792.39 & 3772.93 & 4379.21 & 0.183 & 0.993 \\
\hline-1.12 & 740.19 & 19186.75 & 3030.06 & 4209.71 & 0.180 & 0.994 \\
\hline
\end{tabular}



FIGURE 13: Illustration of the improved Burgers creep model.

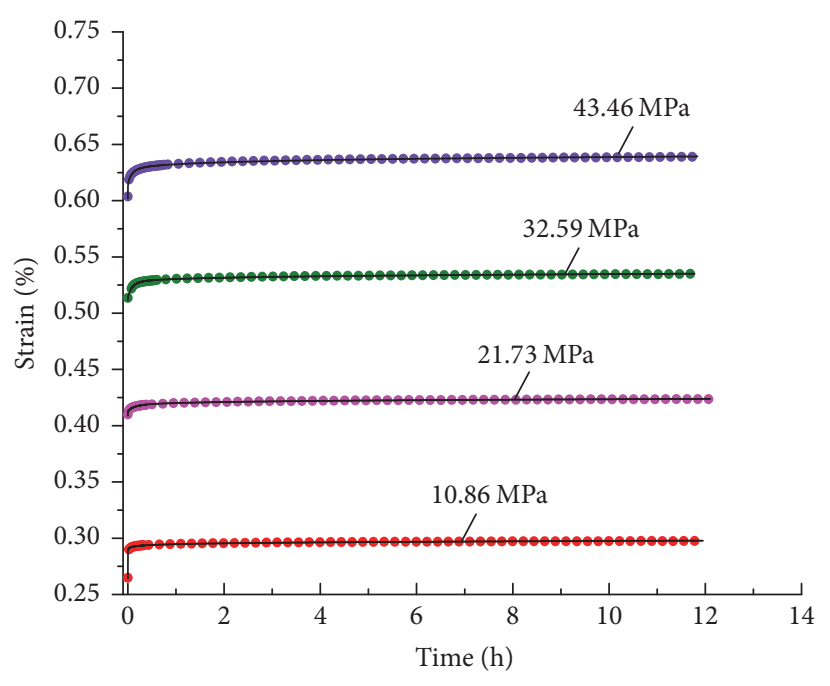

- Experimental curves

— Theoretical curves

(a)

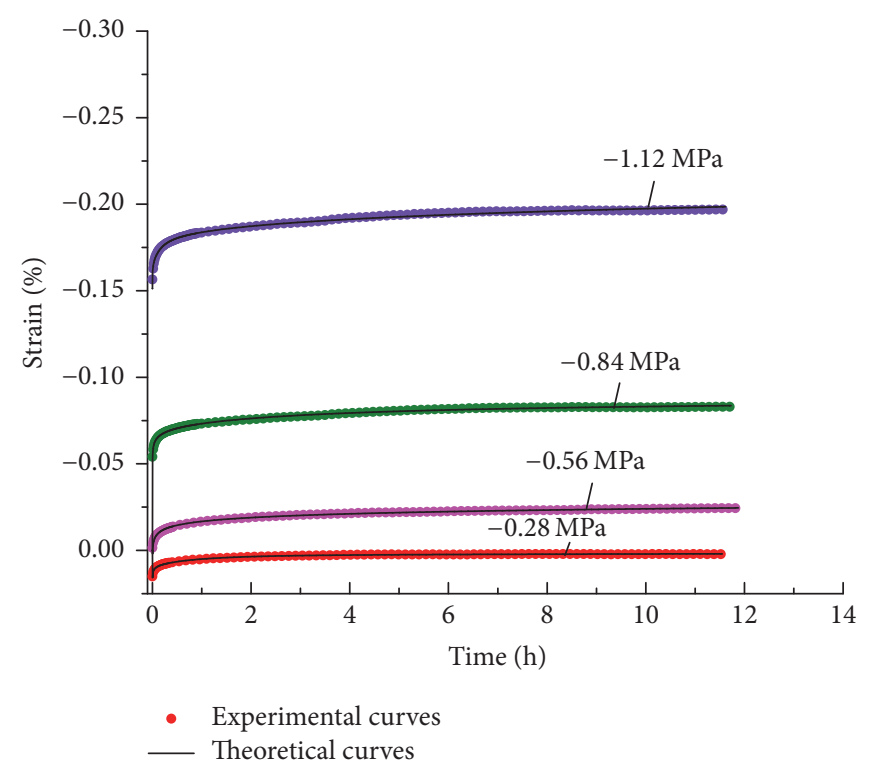

(b)

FIGURE 14: Comparison between improved Burgers creep model curves with the experimental result (a) under compressive stress and (b) under tensile stress.

Figure 15 presents a comparison of the Burgers creep model curves and the improved Burgers creep model curves with experimental results for red sandstone. From Figures 14 and 15 and Table 2, it is found that the calculated results of the proposed improved Burgers model are in good agreement with the tested results. The correlation coefficient square $\left(R^{2}\right)$ of three curves is more than 0.982 , which indicates the prediction precision of the improved Burgers creep model in simulating the properties of the sandstone under incremental uniaxial cyclic compressive and tensile loading.

\section{Conclusion}

In this paper, the results of short-term and creep experiments on red sandstone specimens under uniaxial incremental cyclic compressive and tensile loading are reported. In 


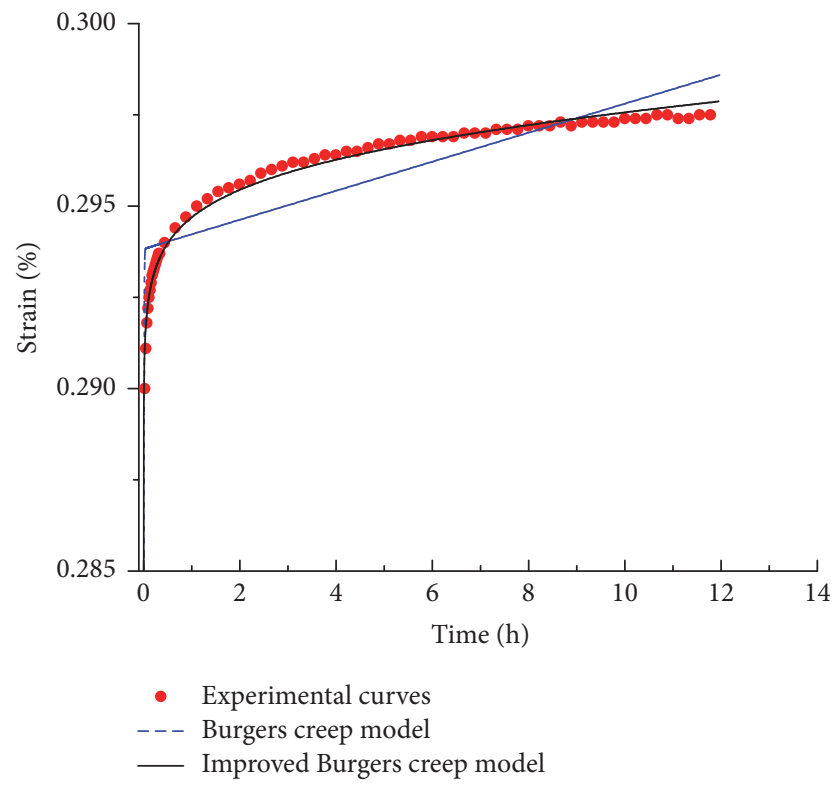

(a)



(b)

FIGURE 15: Comparison between calculated results and experimental results (a) under compressive stress of $10.86 \mathrm{MPa}$ and (b) under tensile stress of $-0.28 \mathrm{MPa}$.

accordance with the experiment results, deformation characteristics and energy dissipation of red sandstone under short-term cyclic loading were analyzed, and the Burgers and the improved Burgers creep model of rocks were used to evaluate the creep behavior of red sandstone. Based on our experimental and modeling results, the following conclusions can be drawn:

(1) In accordance with the short-term uniaxial experimental results of red sandstone under cyclic loading, the curve of stress-axial strain formed hysteretic loops after each cyclic loading and the area of the hysteretic loops increased with the loading stress. The stressstrain curves in the compressive loading stages and the tensile loading stages have an obvious memory effect. It was also found that the dissipated energy increased nearly in a power function with the cycle number.

(2) Under each uniaxial compressive or tensile loading, the axial and the lateral creep strain rates increase first and then gradually decrease to a constant value after a period of time. The creep curve under each stress level can be divided into decay and steady stages.

(3) Compared to the traditional Burgers creep model, the proposed improved Burgers creep model has higher prediction precision in simulating the behavior of the sandstone under incremental uniaxial cyclical compressive and tensile loading.

\section{Conflicts of Interest}

The authors declare that there are no conflicts of interest regarding the publication of this paper.

\section{Acknowledgments}

This study was partially supported by the National Natural Science Foundation of China (Grant no. 41302223), Science and Technology Plan Projects of Chongqing Administration of Land, Resources and Housing (KJ-2015047), Chongqing No. 3 Colleges and Universities Youth Backbone Teachers Funding Plan, Chongqing Research Program of Basic Research and Frontier Technology (cstc2016jcyjA0074, cstc2016jcyjA0933, and cstc2015jcyjA90012), and the Scientific and Technological Research Program of the Chongqing Municipal Education Commission (KJ1713327, KJ1600532). The authors also thank Professor Yang Mijia for his valuable suggestions and English improvement of this manuscript, who comes from the Department of Civil and Environmental Engineering, North Dakota State University.

\section{References}

[1] H. Song, H. Zhang, D. Fu, and Q. Zhang, "Experimental analysis and characterization of damage evolution in rock under cyclic loading," International Journal of Rock Mechanics \& Mining Sciences, vol. 88, pp. 157-164, 2016.

[2] A. Momeni, M. Karakus, G. R. Khanlari, and M. Heidari, "Effects of cyclic loading on the mechanical properties of a granite," International Journal of Rock Mechanics and Mining Sciences, vol. 77, pp. 89-96, 2015.

[3] X. Ge, Y. Jiang, Y. Lu, and J. Ren, “Testing study on fatigue deformation law of rock under cyclic loading," Chinese Journal of Rock Mechanics and Engineering, vol. 22, no. 10, pp. 1581-1585, 2003 (Chinese).

[4] L.-J. Ma, X.-Y. Liu, M.-Y. Wang et al., "Experimental investigation of the mechanical properties of rock salt under triaxial cyclic loading," International Journal of Rock Mechanics \& Mining Sciences, vol. 62, pp. 34-41, 2013. 
[5] K. Fuenkajorn and D. Phueakphum, "Effects of cyclic loading on mechanical properties of Maha Sarakham salt," Engineering Geology, vol. 112, no. 1-4, pp. 43-52, 2010.

[6] D. Huang and Y. Li, "Conversion of strain energy in triaxial unloading tests on marble," International Journal of Rock Mechanics and Mining Sciences, vol. 66, pp. 160-168, 2014.

[7] M. He, N. Li, Y. Chen, and C. Zhu, "Strength and Fatigue Properties of Sandstone under Dynamic Cyclic Loading," Shock and Vibration, vol. 2016, Article ID 9458582, 8 pages, 2016.

[8] N. Erarslan and D. J. Williams, "The damage mechanism of rock fatigue and its relationship to the fracture toughness of rocks," International Journal of Rock Mechanics and Mining Sciences, vol. 56, pp. 15-26, 2012.

[9] Y. Zhao, L. Zhang, W. Wang et al., "Creep Behavior of Intact and Cracked Limestone Under Multi-Level Loading and Unloading Cycles," Rock Mechanics and Rock Engineering, vol. 50, no. 6, pp. 1409-1424, 2017.

[10] J. Liu, H. Xie, Z. Hou, C. Yang, and L. Chen, "Damage evolution of rock salt under cyclic loading in unixial tests," Acta Geotechnica, vol. 9, no. 1, pp. 153-160, 2014.

[11] Z. Wang, S. Li, L. Qiao, and J. Zhao, "Fatigue behavior of granite subjected to cyclic loading under triaxial compression condition," Rock Mechanics and Rock Engineering, vol. 46, no. 6, pp. 1603-1615, 2013.

[12] X. S. Liu, J. G. Ning, Y. L. Tan, and Q. H. Gu, "Damage constitutive model based on energy dissipation for intact rock subjected to cyclic loading," International Journal of Rock Mechanics and Mining Sciences, vol. 85, pp. 27-32, 2016.

[13] S. Q. Yang, P. Xu, P. G. Ranjith, G. F. Chen, and H. Jing, "Evaluation of creep mechanical behavior of deep-buried marble under triaxial cyclic loading," Arabian Journal of Geosciences, vol. 8, no. 9, pp. 6567-6582, 2015.

[14] K. Khaledi, E. Mahmoudi, M. Datcheva, and T. Schanz, "Stability and serviceability of underground energy storage caverns in rock salt subjected to mechanical cyclic loading," International Journal of Rock Mechanics and Mining Sciences, vol. 86, pp. 115131, 2016.

[15] B. Y. Zhao, D. Y. Liu, and Q. Dong, "Experimental research on creep behaviors of sandstone under uniaxial compressive and tensile stresses," Journal of Rock Mechanics and Geotechnical Engineering, vol. 3, pp. 438-444, 2011.

[16] B. Y. Zhao, W. Liu, N. C. Xu, and Z. Y. Li, "Development of a rock tensile and compression creep testing machine and its application," Journal of Experimental Mechanics, vol. 31, no. 2, pp. 238-242, 2016 (Chinese).

[17] L. Miranda, J. Milosevic, and R. Bento, "Cyclic behaviour of stone masonry walls strengthened by grout injection," Materials and Structures/Materiaux et Constructions, vol. 50, no. 1, article 47, 2017.

[18] Q. Meng, M. Zhang, L. Han, H. Pu, and T. Nie, "Effects of Acoustic Emission and Energy Evolution of Rock Specimens Under the Uniaxial Cyclic Loading and Unloading Compression," Rock Mechanics and Rock Engineering, vol. 49, no. 10, pp. 3873-3886, 2016.

[19] H. Xie, L. Li, Y. Ju, R. Peng, and Y. Yang, "Energy analysis for damage and catastrophic failure of rocks," Science China Technological Sciences, vol. 54, no. 1, pp. 199-209, 2011.

[20] Y. Zhang, W.-Y. Xu, J.-J. Gu, and W. Wang, "Triaxial creep tests of weak sandstone from fracture zone of high dam foundation," Journal of Central South University, vol. 20, no. 9, pp. 2528-2536, 2013.
[21] P. Cao, W. Youdao, W. Yixian, Y. Haiping, and Y. Bingxiang, "Study on nonlinear damage creep constitutive model for highstress soft rock," Environmental Earth Sciences, vol. 75, no. 10, article no. 900, 2016.

[22] L. Wu, B. Li, R. Huang, and P. Sun, "Experimental study and modeling of shear rheology in sandstone with non-persistent joints," Engineering Geology, vol. 222, pp. 201-211, 2017.

[23] H. Z. Liu, H. Q. Xie, J. D. He, M. L. Xiao, and L. Zhuo, "Nonlinear creep damage constitutive model for soft rocks," Mechanics of Time-Dependent Materials, vol. 21, no. 1, pp. 7396, 2017. 


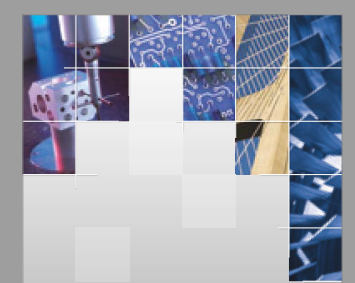

\section{Enfincering}
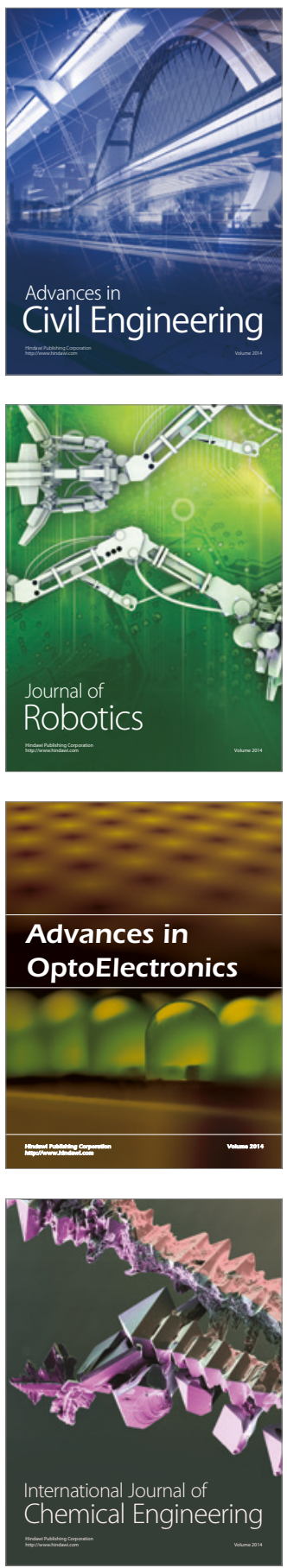

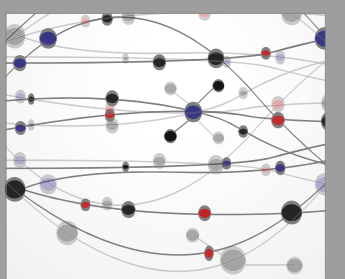

The Scientific World Journal

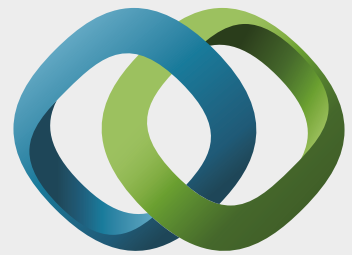

\section{Hindawi}

Submit your manuscripts at

https://www.hindawi.com
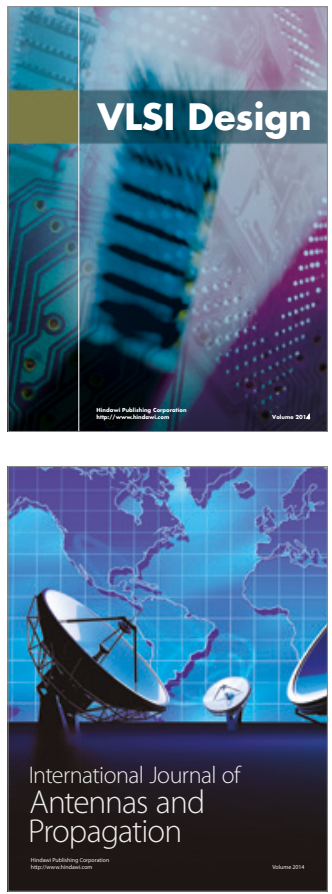

\section{Rotating}

Machinery
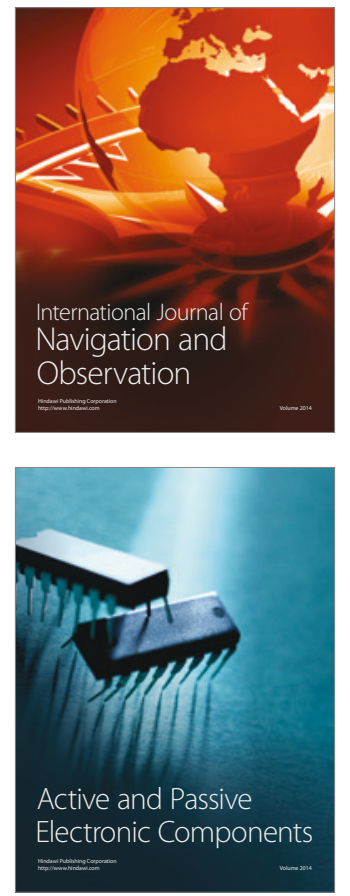
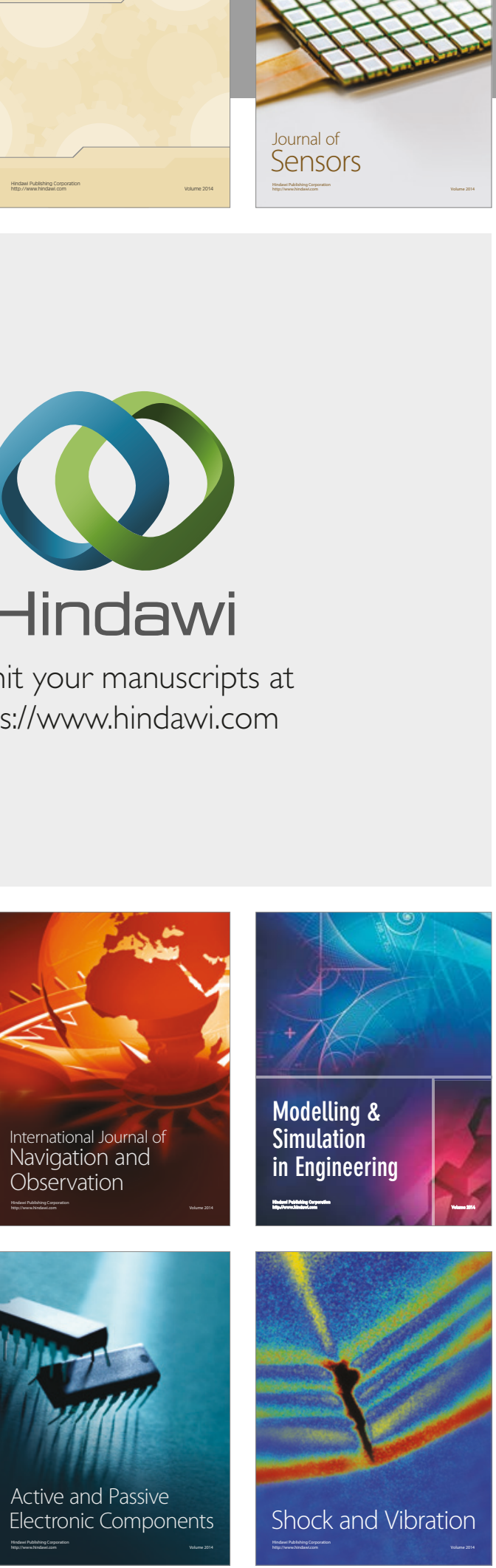
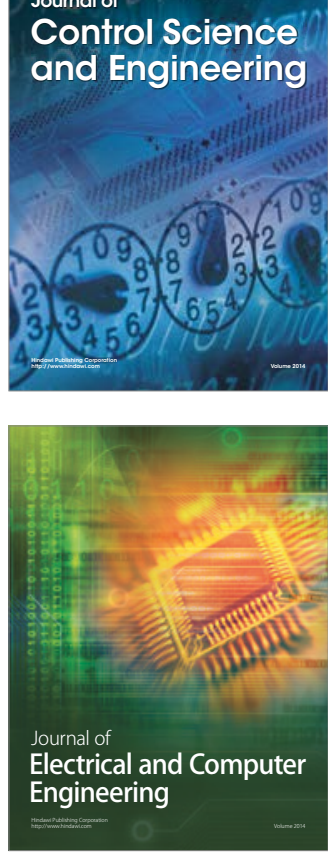

Distributed

Journal of

Control Science

and Engineering
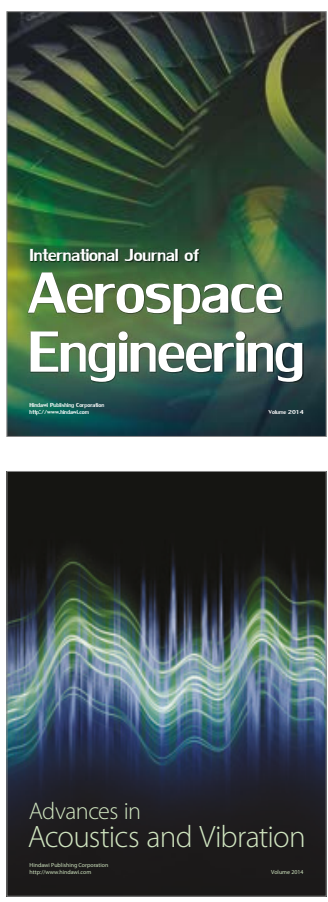

Sensor Networks 